\title{
STUDY ON MARITIME LOGISTICS WAREHOUSING CENTER MODEL AND PRECISION MARKETING STRATEGY OPTIMIZATION BASED ON FUZZY METHOD AND NEURAL NETWORK MODEL
}

\author{
Kefeng Xiao, Ph. D., \\ Xiaolan Hu, Ph. D., \\ Economics and Management School, Wuhan University, Wuhan, 430074, China
}

\begin{abstract}
The bulk commodity, different with the retail goods, has a uniqueness in the location selection, the chosen of transportation program and the decision objectives. How to make optimal decisions in the facility location, requirement distribution, shipping methods and the route selection and establish an effective distribution system to reduce the cost has become a burning issue for the e-commerce logistics, which is worthy to be deeply and systematically solved. In this paper, Logistics warehousing center model and precision marketing strategy optimization based on fuzzy method and neural network model is proposed to solve this problem. In addition, we have designed principles of the fuzzy method and neural network model to solve the proposed model because of its complexity. Finally, we have solved numerous examples to compare the results of lingo and Matlab, we use Matlab and lingo just to check the result and to illustrate the numerical example, we can find from the result, the multi-objective model increases logistics costs and improves the efficiency of distribution time.
\end{abstract}

Keywords: Maritime logistics warehousing center mode; Precision marketing strategy optimization; Fuzzy method; Neural network model; Polarity reversal

\section{INTRODUCTION}

Manufactories, customers and suppliers are important members in a supply chain. To some extent, the success of a manufactory depends on its ability to link these members seamlessly. In the real logistics systems, it often requires some distribution centers to connect manufactories and their customers for the improvement of product flow.

In China and under the condition of socialist market economy, with the gradual perfection of market economy system, and gradually forms a large market, the pattern of circulation, the commodity circulation scale is expanded. The system of China's commodity circulation of commodities trading market [1], represent the future development direction of the domestic spot commodity trading market, the rise and development of commodity trading market are an inevitable trend, so it is important and meaningful to study the circulation of commodities, is also in line with the current trend of commodity circulation. It was widely believed that the source of corporate profits mainly includes two aspects: namely, the reduction of material consumption and raising labor productivity, and now, the industry generally believe that the modern logistics is the third profit source of commercial area for storing mining. Especially in today's society has become a highly developed information society, all kinds of management thoughts, management concept has been widely spread and development, including the development and popularization of the supply chain logistics management, supply chain logistics management at present has become an effective way for enterprises to meet the competition between scholars, once said "competition is not the competition between enterprises, but between supply chain and supply chain competition" [2-3]. Supply chain logistics is the advanced stage of the development 
of logistics management, it is not only confined to like the past, only to consider how to make better use of logistics resources, how to more effectively on distributed geographic market and business activities, modern logistics supply chain management, gives the thought and connotation of the update, the need to form the logistics the logistics network resource has become the key to the efficient operation of the supply chain. China's traditional commodities trading market is not starting from the concept of the whole supply chain, the overall optimization of the logistics network is not, this will make the commodity logistics costs are too high, thus affecting the overall operating costs. Related activities of the logistics distribution center have a very large impact on the modern supply chain logistics, logistics distribution center for the effective utilization of logistics resource, effectively promote the logistics network [4].

\section{OVERVIEW}

The upgrading of technical equipment and logistics service quality improvement, as well as improving logistics investment environment, promoting the growth of the third party logistics enterprises will play a decisive role; its goal is to facilitate the transport of goods as soon as possible toward the development of efficient, integrated and modernized direction. Therefore, to realize the integrated and efficient management of commodity circulation, to accelerate China's commodity circulation, promoting market prosperity, plays a vital role5.

The supply chain management is the transformation of goods from raw materials sites to processing facilities, component fabrication plants, final products assembly plants, distribution centers, retailers and customers. The supply chain management further entails the decisions about (1) what quantity of goods to hold in inventory at each stage of the process, (2) where to produce, what to produce, and how much to produce at each site, (3) how to distribute the products to the customers, (4) where to locate plants and distribution centers.

In recent years the location problems have received considerable attention from academics and practitioners for many public sectors (e.g. clinics, ambulances, etc.) and private organizations (e.g. warehouses, plants, banks, etc.). These problems have a complex decision making process for many reasons, for example:

The problem of distribution centers is also complex because of inefficient location will result in excess costs, being incurred throughout the life time of the facilities, no matter how well the production plans, transportation options, inventory management and information sharing decisions optimized in response to changing conditions. However, a realistic analytical model is difficult to formulate this problem6.

Vehicle routing and inventory decisions are generally secondary to facility location in the sense that facilities are expensive to construct and difficult to modify.
The difficulties of managing a number of service vehicles, the realization of interventions in a time of minimal paths for different sectors of the service region and the satisfaction of requests produced in time and space make the location of emergency facilities very complex.

I have an interest in this research work for locating warehouses and distribution centers, indeed. In the last few years the increase in production economies of scale and the decrease in transportation cost have focused attention on distribution center. Distribution center (DC) is viewed as the competency that links an enterprise with customers and suppliers. In order to reduce transportation cost, enforce operation efficiency and logistic performance, evaluating and selecting a suitable warehouse and DC location one of the most important decision issues for distributions industries. Figure 1 shows the basic logistical model.

\section{MODEL AND ALGORITHM}

The solution of vehicle transportation problem, as the key point in modern logistics intelligent system, is the NP-Hard problem. The optimization of transportation service network and vehicle scheduling can not only reduce the operating costs greatly but also help solving the problem of environment and traffic [7-8].

The method of evaluation function and goal programming (non-intelligent) are often used to solve the multi-objective problem to a specific practice vehicle transportation problem in logistics, I have researched by using the method of neural network model, fuzzy method and fuzzy programming method, which showed a good effect in making the planning table. However, it seems to be under-powered to solve a more complicated model. The other way is to find all the efficient solution. Based in genetic algorithm, Meng and Liu proposed a method called "Multi-agent genetic algorithm "to solve a multi-objective optimization problem, which test on some test function and find some compromise solution that distributed in the Pareto frontier uniformly with less mount of running time. Zhang and Liu proposed the multiobjective method of smooth homology [9-12]. Liu analyzed the convergence of the trace of particle and PSO method and proposed two improved single-objective PSO and two improved multi-objective PSO [13-14]. According to the study of the weakness of traditional PSO, Li designed an adaptive mutation particle swarm optimization algorithm, which achieves good results. However, there are the defects of slow convergence speed in the method above to a specific vehicle programming problem. After a long research work, a new proposed Multi-Population Particle Swarm Algorithm (MPSA) has been adopted to a large vehicles transportation problem (with 54 variables), which perfectly solve it.

Take TC as total cost and TT as total time, considering the choice of warehouses, a large vehicle transportation programming model can be like this: 


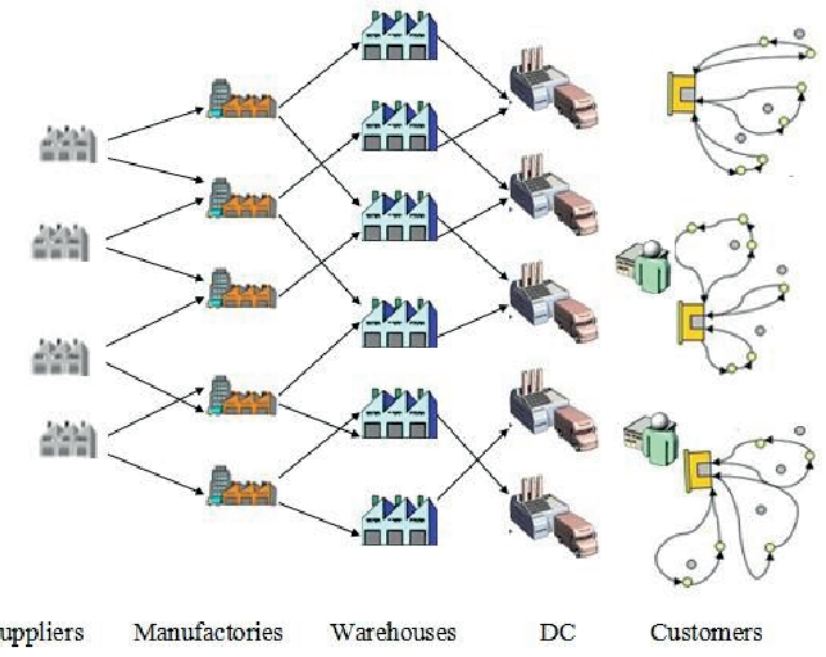

Fig. 1. The basic logistical model

$\ddot{u}^{(\alpha)}(\quad)=\left.\frac{\ddot{u}()}{d x^{\alpha}}\right|_{x=x_{0}}=\lim _{\delta x \rightarrow 0} \frac{\Delta^{\alpha}\left(f(x)-f\left(x_{0}\right)\right)}{\left(x-x_{0}\right)^{\alpha}}$

for $0<a \leq 1$ where

$$
\Delta^{\alpha}\left(f(x)-f\left(x_{0}\right)\right) \cong \Gamma(1+\alpha) \lim _{x \rightarrow \infty} \Delta\left(f(x)-f\left(x_{0}\right)\right)
$$

And local fractional integral of $f(x)$ defined by Eq.3.

$$
\begin{aligned}
& { }_{a} I_{b}^{(\alpha)} f(t)=\frac{1}{\Gamma(1+\alpha)} \int_{a}^{b} f(t)(d t)^{\alpha} \\
& =\frac{1}{\Gamma(1+\alpha)} \lim _{\Delta t \rightarrow 0} \sum_{j=0}^{j=N-1} f\left(t_{\mathrm{j}}\right)\left(\Delta t_{\mathrm{j}}\right)^{\alpha}
\end{aligned}
$$

With $\Delta t_{j}=t_{j+1}-t_{j}$ and $\Delta t=\max \left\{\Delta t_{1}, \Delta t_{2}, \cdots, \Delta t_{j}, \cdots\right\}$, where for $j=1,2, \cdots, N-1,\left[t_{j}, t_{j+1}\right]$ is a partition of the interval $[a, b]$ and $t_{0}=a, t_{N}=b$.

If $f(x)$ is defined on the real line $-\infty<x<\infty$, its local fractional Hilbert transform, denoted by $f_{x}^{H, \alpha}(x)$ is defined by

$$
H_{\alpha}\{f(t)\}=\hat{f}_{H}^{\alpha}(x)=\frac{1}{\Gamma(1+\alpha)} \oint_{R} \frac{f(t)}{(t-x)^{\alpha}}(d t)^{\alpha}
$$

Where $x$ is real and the integral is treated as a Canchy principal value, that is,

$$
\begin{aligned}
& \frac{1}{\Gamma(1+\alpha)} \oint_{R} \frac{f(t)}{(t-x)^{\alpha}}(d t)^{\alpha} \\
& =\lim _{\varepsilon \rightarrow 0}\left[\frac{1}{\Gamma(1+\alpha)} \int_{-\infty}^{x-\varepsilon} \frac{f(t)}{(t-x)^{\alpha}}(d t)^{\alpha}+\right. \\
& \left.\frac{1}{\Gamma(1+\alpha)} \int_{x+\varepsilon}^{\infty} \frac{f(t)}{(t-x)^{\alpha}}(d t)^{\alpha}\right]
\end{aligned}
$$

To obtain the inverse local fractional Hilbert transform, write again Eq. (4) as

$$
\begin{gathered}
\hat{f}_{H}^{\alpha}(x)=\frac{1}{\Gamma(1+\alpha)} \int_{-\infty}^{\infty} \frac{f(t)}{(t-x)^{\alpha}}(d t)^{\alpha} \\
=\frac{1}{\Gamma(1+\alpha)} \int_{-\infty}^{\infty} f(t) g(x-t)(d t)^{\alpha}=f(x) * g(x) \\
\hat{f}_{H}^{\alpha}(x)=\frac{1}{\Gamma(1+\alpha)} \int_{-\infty}^{\infty} \frac{f(t)}{(t-x)^{\alpha}}(d t)^{\alpha} \\
=\frac{1}{\Gamma(1+\alpha)} \int_{-\infty}^{\infty} f(t) g(x-t)(d t)^{\alpha} \\
=f(x) * g(x)
\end{gathered}
$$

The equation of motion is as follows:

$$
\partial_{j}\left(C_{i j k l} \partial_{k} u_{l}+e_{k i j} \partial_{k} \varphi\right)-\rho \ddot{u}_{i}=0
$$

Under the linear theory, that is:

$$
\partial_{j}\left(e_{i j k l} \partial_{k} u_{l}-\eta_{k i j} \partial_{k} \varphi\right)=0
$$

Figure 3 shows the calculation flow of PSO. The analysis of some change summary of logistics distribution in the electronic commerce mode: e-commerce logistics distribution center location has the tradition of expenditure cost oriented began the transition to the distribution efficiency oriented; In the traditional logistics distribution center to costs or expenses to minimize the location condition, this algorithm is mainly based on the distribution of maximizing the efficiency of location, in the storage area is no longer the decision role in the case, a detailed analysis of the electronic commerce logistics distribution center and the factors affecting the change in level analysis with appropriate weight to each effect factor analysis of ways to find more suitable location scheme under the model of electronic commerce, provides a new idea for the logistics distribution center under the electronic commerce site.

To improve the logistic distribution center under electronic for GDPE, some factors of general logistics distribution center location should be pay more attention in the process of selecting the location of logistics distribution and Long term electronic trading rules from stock. Figure 3 shows scheduling result by using the fuzzy method of the average operator (PP). 


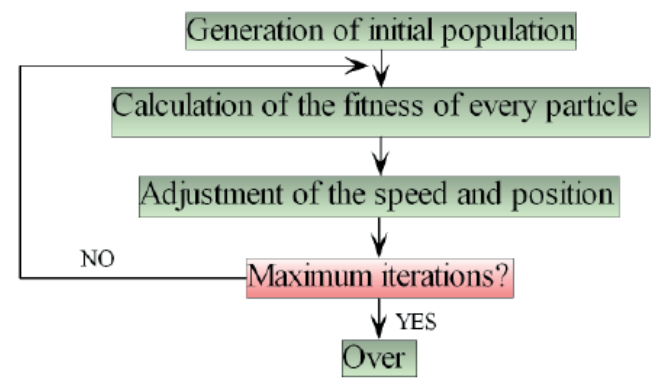

Fig. 2. The calculation flow of PSO

Transaction mode exchange has the following characteristics:

1 electronic trading system to focus the national or the region of the majority of buyers and sellers, to form a unified-big market, reduce intermediate links and widen the channels of business, and ultimately reduced transaction costs, trading gains and efficiency.

2 avoid the risk of price fluctuation: the buyer can control the cost of raw materials, to circumvent the impact raw material price fluctuations on enterprise production activities. The seller can be determined in advance of product sales price, locking the product production profit.

3 strong financing supports. In order to solve the plastic trading of short-term liquidity difficulties of both sides, the exchange introduced the settlement bank financing Guarantee Corporation and professional to provide delivery of warehouse receipts pledge to provide plastic dealers and other services.

4 credit guarantee. All electronic transaction mode, not only can reduce the transaction costs of enterprises, but also provides the delivery of credit guarantee, avoid debt disputes.

In the reality, many other factors except cost and time need to consider such as inventory cost, vehicle routing problem (VRP), public satisfaction, social benefit, covering scope of distribution center and etc... Therefore, next work is to concentrate on establishing a multilevel logistic warehouse distribution mechanism under vehicle routing problem and detailing selecting model.

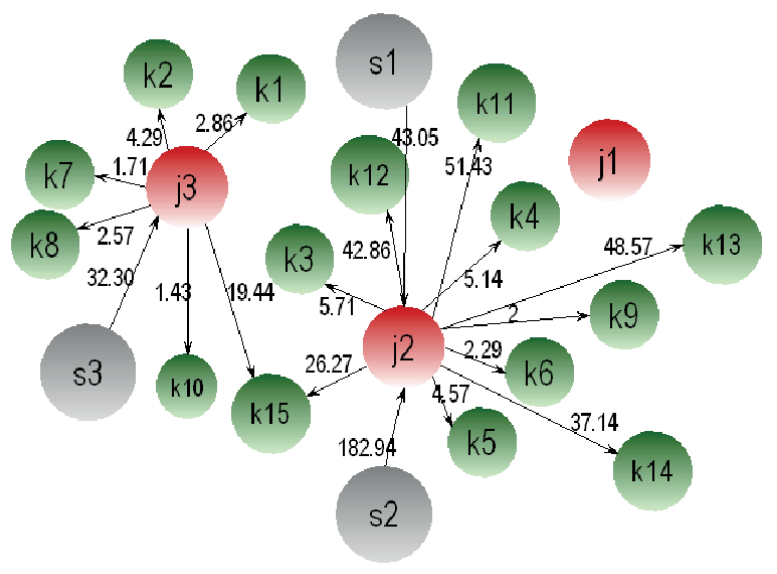

Fig. 3. Scheduling result by using the fuzzy method of the average operator (PP)

\section{RESULTS AND DISCUSSION}

The paper uses VENSIM PLE to set model and emulate. System Dynamics can predict higher order complex timevarying systems of nonlinear and time-delay applicator qualitative and quantitative to solve the social, economic and other complex large system problems. VENSIM simulation software is an important part of System Dynamics, so the paper uses VENSIM PLE to meet the needs of this study. The flow chart is shown as Figure 4.

The remanufacturing process makes the enterprise logistics, cash flow and information flow to form closedloop supply chain. Remanufacturing, however, preserves the shape and added value of products since the remanufactured product should be used for the same purpose it had during its original lifecycle, since the remanufacturing process preserves part of the raw materials and value added to the product during its fabrication, allowing companies to increase their productivity and profitability, however, it is difficult to achieve an integrated and systematic vision of all the issues involved in remanufacturing. Remanufacturing is a complex business due to the high degree of uncertainty in the production process, mainly caused by two factors: the quantity and the quality of returned products. In view of this, the quality control of remanufacturing priority closed-loop supply chain research has realistic significance.

Nowadays, big data has become an important direction of development of modern information technology, and sharing and analysis of big data would not only bring immeasurable economic value, but also play a significant role in promoting the development of society. Big Data-as-a-Service (BDaaS) is a new data resource usage pattern and a new form of service economy, by encapsulating heterogeneous data; it can provide ubiquitous service consumers, standardization, and on-demand services, including search, analysis or visualization.

Through a comprehensive analysis of underground logistics system and user needs, underground logistics monitoring system based on internet of things technology should have the following features:

1) Acquisition and display name logistics, area, location, traffic conditions near fees and billing methods, the surrounding traffic and other data transfer methods.

2) Logistics managers need to understand the use of logistics spaces per vehicle entry / open a case, enter basic information about vehicle logistics, logistics reservation information, traffic information. Underground car parks are major convenience manager's logistics lot to maintain order and ensure safety of vehicle logistics, a timely change and adjust management strategies, improve operational efficiency.

3) Every car logistics shall have a uniform means of identification (eg RFID tags), the owner of the information is correct logistics of vehicles, vehicle information, logistics information logo.

4) A variety of information gathering nodes with data collection and transmission capabilities to facilitate 
installation and post-inspection, maintenance, data to be able to achieve rapid and effective treatment to ensure reliable access to information. Table 1 shows the evaluation index system of warehousing logistics transportation responsibility.

5) To have a full range of monitoring systems, as well as realtime monitoring of environmental quality in a car park, and the logistics lot to the user managers to provide better service and work environment.

6) To finally achieve cars and cars, people and cars, people and people contacted, user-friendly logistics and pick up the car, easy to manage scheduling managers to create better indoor logistics traffic order, to ensure safety. Table 2-4 shows the experiment result.

In behavior analysis area, it still faces four challenges:

1) There is no standardized, user experience based BDaaS architecture which can shield the complexity of data sources and operations;

2) The lack of generic unstructured data model which reflects user behavior characteristic, made BDaaS for unstructured data difficult to build;

3) Existing data model follows the Web services model, however, so far, holistic BDaaS service model with the characteristics of big data has not yet appeared;
4) There is no appropriate solution in providing data retrieval, analysis and visualization services and optimizing service capacity.

The objective of TT and TC are contradictory seen in essence, thus the best solution should be replaced by the no inferior solution, which could not be better without consideration of the cost of other objective. Figure 5 shows the search sketch of double objective TT\&TC. This method produces a set of non-inferior solution or approximate one by MPSA. The decider chooses the most satisfactory noninferior solution by themselves. To get a set of non-inferior solution (Pareto Frontier) for such a double objective function, an adaptive technique can be established to compel the initial solution to the Pareto Frontier. After the update of the populations (S1, S2, S3...), it will approach the Pareto Frontier. Two important issues should be considered in designing the algorithm; the first one is, guarantee of the diversity of the population, the second one is to control the evolutionary direction. Measures should be made to prevent the population from converging into one solution, in order to keep the diversity of non-inferior solution. Figure 6 shows the sketch map of Multi-Population Particle Swarm Algorithm with random parameters (MPSA).

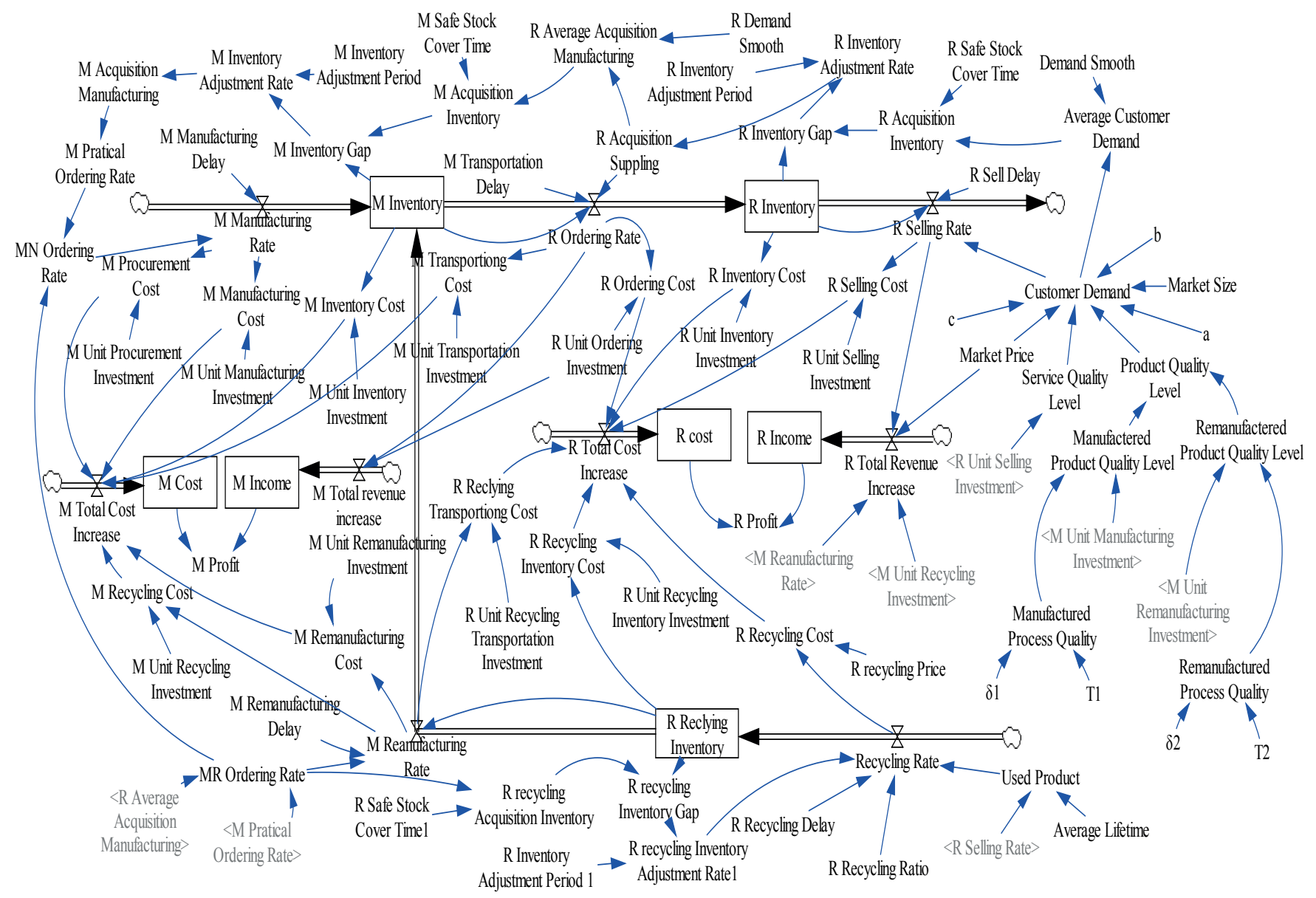

Fig. 4. Flow chart 


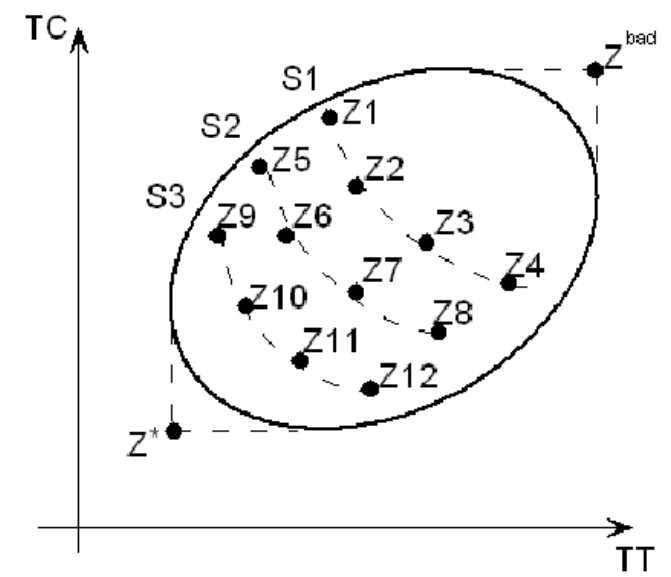

Fig. 5. The search sketch of double objective TT\&TC

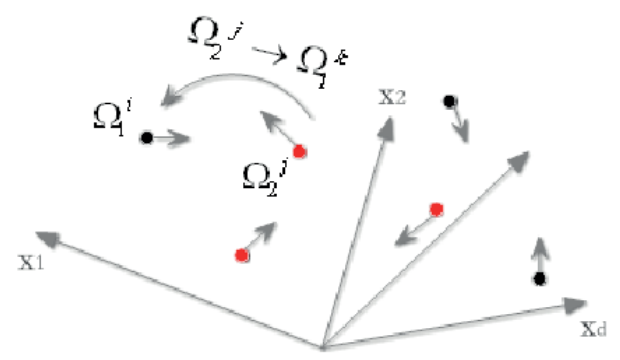

Fig. 6. Sketch map of Multi-Population Particle Swarm Algorithm with random parameters (MPSA)

It is a critical issue to deal with the constraints well when we use PSO. The most widely used methods are based on the penalty function method currently. However, the best values of the new objective function adding the penalty factor are rely on the choice of penalty factor. When we choose a smaller one, the best value of the new objective function may not be the right one; when we choose a larger one, too much locally optimal solution may occur outside the feasible region.

Penalty function method is adopted in this model. We add one large $\mathrm{M}$ to the particulars which it does not satisfy per constraint. For every equality constraint, we eliminate one variable by adding one inequality constraint for that variable equally. Solution space has a lot of non-feasible solution because of the constraint and we can take some measures to narrow the search-range according to the observation of the constraints, or the convergence speed will be slow.

Compare the three methods, we find that MPSA is more effective overall while fuzzy method can give result based on the satisfaction of decision-maker, which is much more based on experience. MILP is good as well, but the applicability become worse once the objective function gets more complex. No matter which method applied, optimal results are better than the company's initial data. Through the virtual peer to frontier in figure 7, it seems that MPSA is better than the fuzzy method. Finally, under the framework of electronic logistics optimization system, taking MPSA as the basic optimization method, a software called E commerce logistics system was developed through Matlab-GUI environment.
Decision- maker not only can get the static optimization plan but also can change the basic information of the suppliers, warehouses and customers in dynamic condition.

Before using the method-Multi-Population fuzzy algorithm proposed in section 3, we can see how ordinary PSO algorithm performs to solve such a transportation problem. Take the total time TT by a single population of particle swarm optimization (PSO) algorithm as example. Figure 8 and Figure 9 are convergence graph of TT of product PP, computing twice, respectively. For Figure 8 and Figure 9, it shows the discreteness of single population PSO and particle swam traps into local optimum after a few times of iterations. I once solve the problem by linear programming of simplex method to the same vehicle transportation problem, one of which is weight method. Run the program by Matlab by taking different weight values, we can get the exact Pareto frontier Electronic-commerce logistics system refers to combining all the moving goods, transport machine, storage equipment, personnel contact and communication in a certain space to be an organism which has special function. It aimed to do the logistics system programming, managing, and control, and can choose the best logistics scheme or find the approach that can improve economic performance and reduce logistics cost in it.

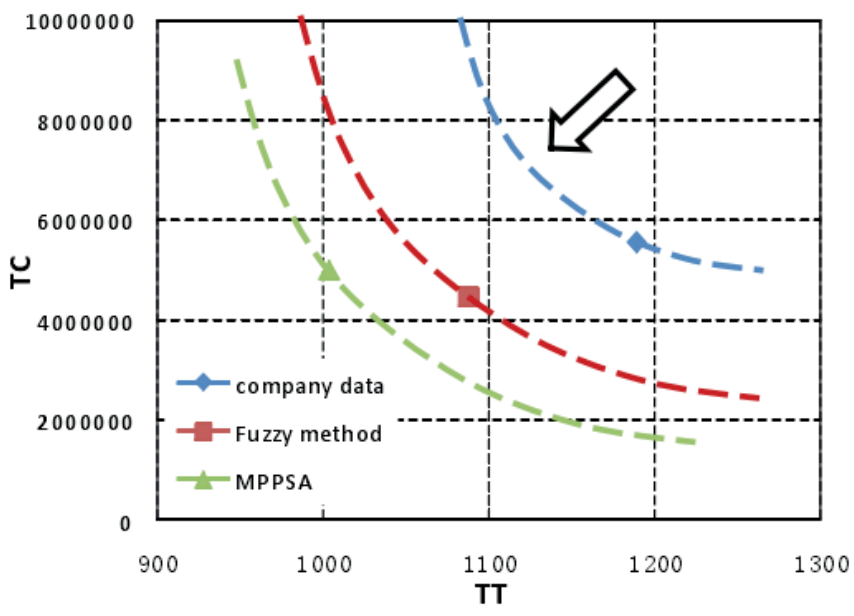

Fig. 7. Comparison of [TT, TC] of company data, Fuzzy method and MPPSA

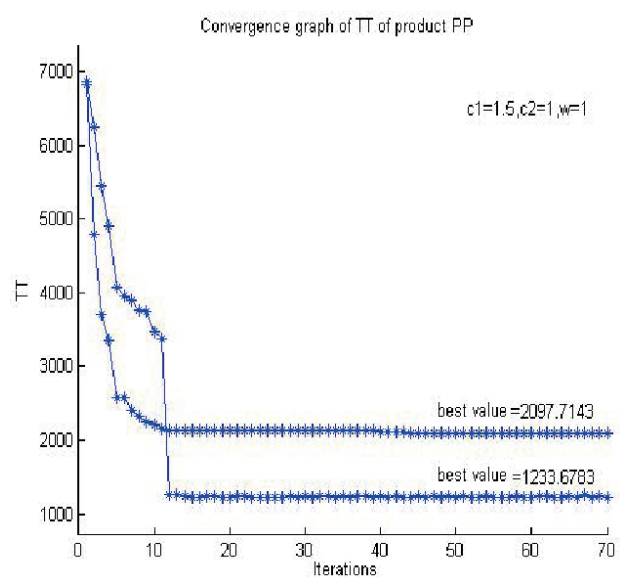

Fig. 8. Convergence graph of TT of product PP in case 1 
The common analysis method of system optimization includes optimization method and simulation method. The former approach achieve by mathematical programming methods or intelligence algorithm, such as the proposed multi-population particle swarm Algorithm with random parameters. However, in addition to the static optimization calculation, a dynamic and revisable system for decisionmaker also needs to be established for achieving managing systematically.

Electronic-commerce logistics system designed in this paper consist of (1) data input module (with data check and change), (2) algorithm module (based on multi-population particle swarm Algorithm), (3) result displaying module. Generally, objective entities related in this model is suppliers, warehouses, customers and vehicles. Data needs are the values of this entities, preparing basic data such as address information, geographic position, demand information, routing information etc. including, which from management information system in enterprise. This part forms the whole logistics network optimization data part of master data. Data import function is in charge of the input information of electronic commerce logistics network system, and it provides a fast and easily update-able interface for user in the meantime.

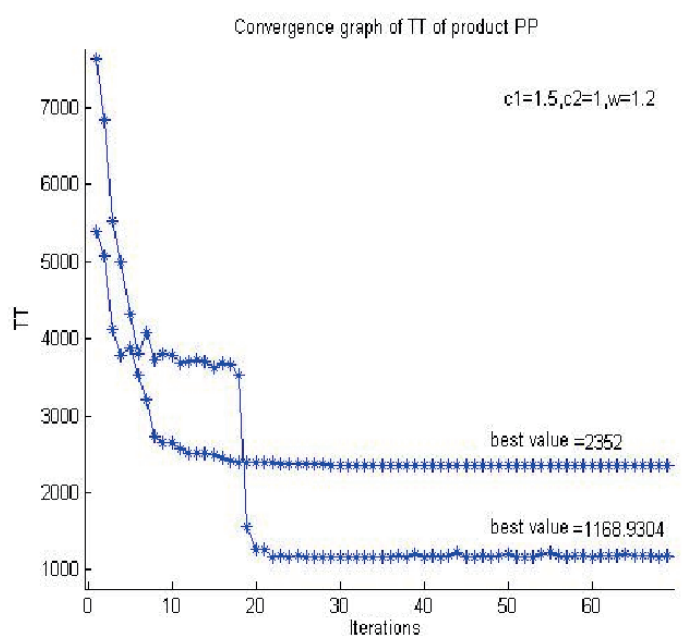

Fig. 9. Convergence graph of TT of product PP in case 2

Tab. 1. The evaluation index system of warehousing logistics transportation responsibility

\begin{tabular}{|c|c|c|}
\hline Responsible for all the stakeholders & The evaluation index & Calculation formula \\
\hline responsibility for creditors & quick ratio & (current assets- inventory) / current liabilities \\
\hline responsibility for employees & Employee wage growth rate & $\begin{array}{l}\text { (total wages in current period - total wages in previous period) / total } \\
\text { wages in previous period }\end{array}$ \\
\hline \multirow{2}{*}{ responsibility for customers } & growth rate of prime business & $\begin{array}{l}\text { (prime business revenue in current period - prime business revenue in } \\
\text { previous period) / prime business revenue in previous period }\end{array}$ \\
\hline & cost rate of prime business & prime business cost/prime business revenue \\
\hline \multirow{2}{*}{ responsibility for providers } & velocity of accounts payable & $\begin{array}{l}\text { prime business cost }+ \text { ending inventory - beginning inventory / } \\
\text { average balance of accounts payable }\end{array}$ \\
\hline & cash accounts payable rate & net cash flow from operating / accounts payable \\
\hline \multirow{2}{*}{ responsibility for community } & employment growth rate & $\begin{array}{l}\text { (number of employees in current period - number of employees in } \\
\text { previous period)/number of employees in previous period }\end{array}$ \\
\hline & public donation expenditure rate & donation expenditure / current sales \\
\hline
\end{tabular}

Tab. 2. Inspection model: Name and Meaning of each variable

\begin{tabular}{|l|l|l|l|}
\hline \multicolumn{1}{|c|}{ Variable nature } & \multicolumn{1}{|c|}{ variable name } & variable symbol & \multicolumn{1}{c|}{ calculation method } \\
\hline explanatory variable & The previous asset value-added rate & VAPAit-1 & $\begin{array}{l}\text { (Employees' salary + Interests + Tax + Dividend + Retained } \\
\text { earnings)/Average total assets, }\end{array}$ \\
\hline explained variable & Corporate social responsibility & CSRit & $\begin{array}{l}\text { Synthesizing an indicator with the help of all the indicators and } \\
\text { the weight given to each stakeholder can reflect corporate social } \\
\text { responsibilities }\end{array}$ \\
\hline
\end{tabular}


Tab. 3. Regression results of the overall sample panel data model and corresponding statistical test results

\begin{tabular}{|c|c|c|c|}
\hline Explanatory variables & Coefficient estimates $\mathbf{B}$ & P values & Adjusted R $^{\mathbf{2}}$ \\
\hline VAPAit-1 & 0.667 & 0.001 & 0.181 \\
\hline
\end{tabular}

Note: ${ }^{*}{ }^{* *}$ and ${ }^{* * *}$ represent the significant correlation when the value is $10 \%, 5 \%$ and $1 \%$ respectively. The table shows the results after calculating.

Tab. 4. Regression results of the warehousing logistics transportation panel data model and corresponding statistical test results

\begin{tabular}{|c|c|c|c|c|}
\hline & public undertaking & commerce & real estate & industry \\
\hline Coefficient estimates B & 0.182 & 0.248 & 0.322 & 0.287 \\
\hline P values & 0.000 & 0.002 & 0.001 & 0.002 \\
\hline Adjusted R ${ }^{2}$ & 0.391 & 0.189 & 0.265 & 0.003 \\
\hline F statistics & 16.463 & 11.125 & 13.254 & 0.124 \\
\hline
\end{tabular}

Note: ${ }^{*}{ }^{* *}$ and ${ }^{* * *}$ represent the significant correlation when the value is $10 \%, 5 \%$ and $1 \%$ respectively. The table shows the results after calculating.

\section{CONCLUSION}

The location of logistics distribution center as an important part of logistics system planning, received more and more scholars and enterprises. The development of e-commerce logistics distribution mode with the change, but also has significant influence on the location of logistics distribution center. How to make reasonable planning of logistics distribution center has the important meaning to the development of the whole logistics system and logistics industry. In this paper, through the analysis of the influence of logistics distribution center under the environment of e-commerce site factors change, using MILP, Fuzzy method and swarm intelligent program to study the logistics distribution center location problem. The traditional logistics center location is based on the characteristics analysis of change of logistics distribution under electronic commerce, for example for site selection and validation. The Multi-Population Particle Swarm Algorithm (MPSA) with random parameters has a good trait of convergence. Further conclusion that MPSA suits for any complicated objective function can be made due to the fact that it get a good Pareto frontier in linear case. The further study can be the logistics mechanism, from which the more realistic model can be made. Solving that model by the new proposed MPSA will help forming a more advanced model.

\section{BIBLIOGRAPHY}

1. Psaraftis H N: Green Maritime Logistics: The Quest for Win-win Solutions. Transportation Research Procedia, Vol. 14, pp. 133-142, 2016.

2. Parola F, Satta G, Panayides P M: Corporate strategies and profitability of maritime logistics firms. Maritime Economics \& Logistics, Vol. 17, no. 1, pp.52-78, 2015.
3. Bell M G H, Meng Q: Special issue in Transportation Research Part B - Shipping, port and maritime logistics. Transportation Research Part B Methodological, Vol. 93, pp. 697-699, 2016.

4. Seo Y J, Dinwoodie J, Roe M: The influence of supply chain collaboration on collaborative advantage and port performance in maritime logistics. International Journal of Logistics, Vol. 19, no. 6, pp. 1-21, 2016.

5. Wang, S.j., Yuan, P., Li, D., Jiao, Y.H.: An overview of ocean renewable energy in China, Renew Sustain Energy Rev, Vol. 15, no. 1, pp. 91-111, 2011.

6. López, I., Andreu, J., Ceballos, S., Alegría, I.M.D., Kortabarria, I.: Review of wave energy technologies and the necessary powerequipment, Renewable and Sustainable Energy Reviews, Vol. 27, no. 6, pp. 413-434, 2013.

7. Coiro, D.P., Troise, G., Calise, G., Bizzarrini, N.: Wave energy conversion through a point pivoted absorber: Numerical and experimental tests on a scaled model, Renewable Energy, Vol. 87, no. 1, pp. 317-325, 2016.

8. Martínez, M., Molina, M.G., Machado, I.R.: Mercado, P.E., Watanabe, E.H., Modelling and simulation of wave energy hyperbaric converter (WEHC) for applications in distributed generation, International Journal of Hydrogen Energy, Vol. 37, no. 9, pp. 14945-14950, 2012.

9. Gaspar, J.F., Calvário, M., Kamarlouei, M., Guedes Soares, C.: Power take-off concept for wave energy converters based on oilhydraulic transformer units, Renewable Energy, no. 86, pp. 12321246, 2016.

10. Yang, L., Hals, J., Moan, T.: Analysis of dynamic effects relevant for the wear damage in hydraulic machines for wave energy conversion, Ocean Engineering. Vol. 37, no, 13, pp. 1089-1102, 2010. 
11. Falcão, A. F. de O.: Modelling and control of oscillating-body wave energy converters with hydraulic power take-off and gas accumulator, Ocean Engineering, Vol. 34, no. 14-15, pp. 20212032, 2007.

12. Virvalo, T.: Hydraulic systems in wave energy application, 1st edn, World Publishing Corporation, China, pp. 56-60, 2009.

13. Lin, Y, G., and Huang, W., Zhang, D.F., Li, W., Bao, J.W.: Application of Hydraulic System in Wave Energy Converter, Electrical, Information Engineering and Mechatronics 2011, Lecture Notes in Electrical Engineering. Vol. 138, pp. 275-283, 2012.

14. Wang, C.W., Jiao, Z.X., Wu, S., Shang, Y.X.: An experimental study of the dual-loop control of electro-hydraulic load simulator, Chinese Journal of Aeronautics, Vol. 26, no. 6, pp. 1586-1595, 2013.

\section{CONTACT WITH AUTHOR}

Kefeng Xiao, Ph. D.

e-mail:2373751844@qq.com

tel.: 18807107080

Economics and Management School Wuhan University

Wuhan Hubei 430074

China 